\title{
Results of hydraulic tests of the ACO Qmax system pipeline
}

\author{
Yuliya Bryanskaya $^{1 *}$, and Aleksandra Ostyakova ${ }^{1,2}$ \\ ${ }^{1}$ National Research Moscow State Civil Engineering University, Moscow, Russia \\ ${ }^{2}$ Water Problem Institute RAS, Moscow, Russia
}

\begin{abstract}
Polymer corrugated pipelines are a very promising type of construction that has many advantages over concrete and reinforced concrete structures that are widely used today for collecting and diverting surface runoff from residential areas and enterprise sites. To collect and divert surface runoff from residential areas and enterprise sites, the hydraulic characteristics of the drainage system made of corrugated polymer culverts of ACO Qmax are studied by computational and experimental methods. The experiments were carried out in the laboratory of Hydraulics and hydro-mechanics at different flow rates and different slopes. The kinematic and dynamic characteristics of the water flow in the pipeline were determined: the velocity, the roughness coefficient, and the hydraulic resistance coefficient were measured at different values of the pipeline filling. It is found that the characteristics of the water flow obtained by the computational method using a computer program differ from the experimental values, the reason for which, apparently, in the shortcomings of the computational program and the lack of accuracy of experimental measurements. Experimental studies were conducted to adjust the calculation methods of such pipelines used in the design and verification of hydraulic calculation methods of corrugated pipelines based on the software product ACO Qmax.
\end{abstract}

\section{Introduction}

Currently, pipelines made of polymer materials are widely used in the construction of various engineering systems. Pipelines made of polymer materials are used in public utilities, hydraulic engineering, transport infrastructure, and other industries [1, 2, 4-6]. In the water sector, pipelines made of polymer materials [1-3] are increasingly used to divert surface runoff; they operate both in non-pressure and pressure mode. The use of such pipelines is very promising; they have several advantages compared to reinforced concrete and metal due to their adaptability, durability, environmental friendliness, and costeffectiveness in construction and operation.

To increase the reliability and efficiency of various engineering structures, accurate hydraulic calculations and knowledge of the hydraulic characteristics of polymer pipelines are required. Even though polymer pipelines have been used for several decades, new modifications are constantly appearing on the market, the hydraulic characteristics of

*Corresponding author: mgsu-hydraulic@yandex.ru 
which, as a rule, are not studied. Since the hydraulic characteristics of pipelines are determined by the technology of their manufacture and the material from which the pipes are made, they vary widely. The effectiveness of their application can be evaluated experimentally and confirmed by calculation. Therefore, for each specific case, it is necessary to conduct hydraulic tests and determine the characteristics of the pipe experimentally. Polymer pipelines of the ACO Qmax system have appeared recently; they are used as slotted drainage systems to collect rain runoff. The range of pipeline sizes is represented in a wide range of $150-900 \mathrm{~mm}$, which allows for variability in the optimization of hydraulic circuits. The production of these pipelines is carried out by casting from polyethylene. As a result, the inner surface is a system of constrictions and extensions. Due to the complex structure of the inner surface, the resistance of the described polymer pipeline can only be determined experimentally.

The purpose of the study was to study the hydraulic characteristics of the polymer pipeline of the ACO Qmax system. The research objective was to conduct experimental studies of the behavior of polymer piping systems ACO Qmax, evaluate measured hydraulic characteristics of the culvert polymer piping systems ACO Qmax diameter 22.5 $\mathrm{cm}$, and the comparison of the obtained characteristics with the results of computer calculation program ACO Qmax. In the course of the experiments, the operating modes of the polymer pipeline were evaluated at different slopes of the bottom of the laboratory channel in which the pipeline was installed, at different degrees of filling of the pipeline. Thus, the article presents experimental studies of the hydraulic resistance of the corrugated polymer pipelines of the ACO Qmax system.

In the literature, there are domestic [1-26] and foreign researchers [27-35] devoted to the study of hydraulic resistance in pipes under various conditions.

\section{Methods}

\subsection{Purpose of the study}

The article assesses the hydraulic characteristics of the ACO Qmax corrugated polymer pipeline culvert with a working diameter of $22.5 \mathrm{~cm}$, used by «Mosvodokanal» as a storm drainage structure in Moscow. Under the given working conditions in the laboratory of hydraulics and hydromechanics of the NRU MGSU, the hydraulic characteristics of the water flow in the studied pipeline system were experimentally evaluated, and under the same conditions, the obtained characteristics were compared with the results of computer calculation using the ACO Qmax program.

The operation modes of the corrugated pipeline were evaluated at various slopes of the bottom on which the pipeline was installed, during thawing of various filling of the pipeline and when simulating the filling of the lower part of the pipeline within the corrugation.

\subsection{Description of the laboratory installation}

The basis of this work on the study of the hydraulic characteristics of a corrugated pipeline is physical modeling and comparison with computer calculation. The experiments were conducted in the laboratory channel of the laboratory of hydraulics and hydromechanics NRU MGSU (G.U.N.T. Gerätebau GmbH (Germany)) [8], the description of which is given in figurel. 


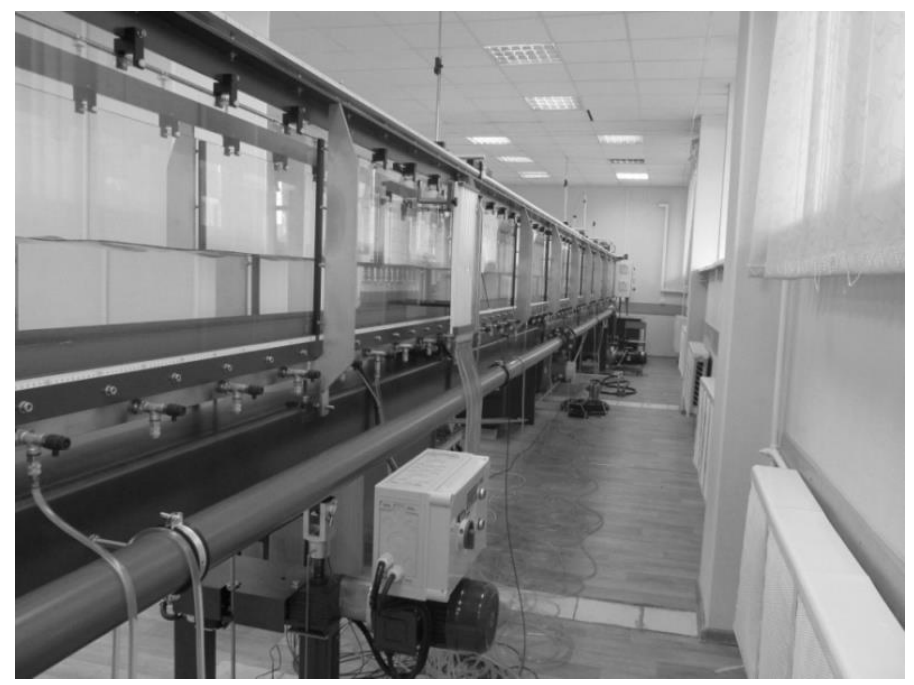

Fig. 1. Laboratory Hydraulic Channel

The laboratory tray of the NRU MGSU is additionally equipped with a flow meter, a control panel (console) for operating the tray, a remote control switch for the laboratory tray, a control panel for the slope of the tray, a control computer with a system, standard, office and specialized software.

Main characteristics of the laboratory channel:

- the total length of the channel is $15.5 \mathrm{~m}$, the length of the working section of the channel $L=12.5 \mathrm{~m}$;

- channel cross-section: width $B=311 \mathrm{~mm}$, depth $H=450 \mathrm{~mm}$;

- channel slope $i$ from $+2.5 \%\left(1.4^{\circ}\right)$ to- $0.5 \%\left(0.28^{\circ}\right)$;

- channel walls made of tempered glass, stainless steel bottom;

- end tanks made of fiberglass reinforced plastic;

- Promag 10D80 electromagnetic flowmeter, accuracy class 0.3 , with measuring range $Q=0-150 \mathrm{~m}^{3} / \mathrm{h}$

- when the working section is completely filled, the bottom deflection of the tray is less than $1 \mathrm{~mm}$, the deflection of the side walls is less than $0.5 \mathrm{~mm}$;

- power supply $380-400 \mathrm{~V}, 50 \mathrm{~Hz}, 3$ phases, rotary pump shutter with manual adjustment. Embedded software of the HM162 tray allows real-time control of the experiment and the collection of experimental data. The water circulation in the channel is carried out by a $4.0 \mathrm{~kW}$ centrifugal pump, supplying a maximum water flow rate of $36 \mathrm{l} / \mathrm{s}$ from four interconnected anticorrosion tanks mounted on the floor of the laboratory hall. The water flow $Q$ is controlled by the speed of the impeller of the pump. The flow rate is measured by an electromagnetic flow meter (figure 2a) [9] and is fixed on the display of the control console (figure $2 \mathrm{~b}$ ) and the computer monitor. If necessary, at intervals of $1 \mathrm{sec}$, the measured values of the skipped flow are recorded in a file on the hard disk of the control computer. 


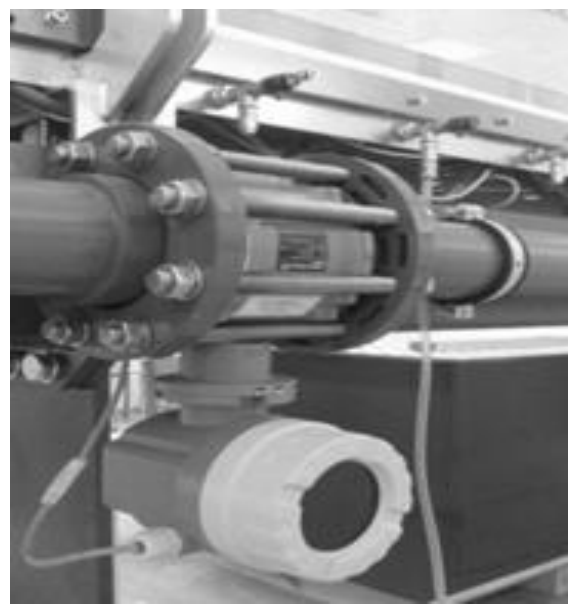

a)

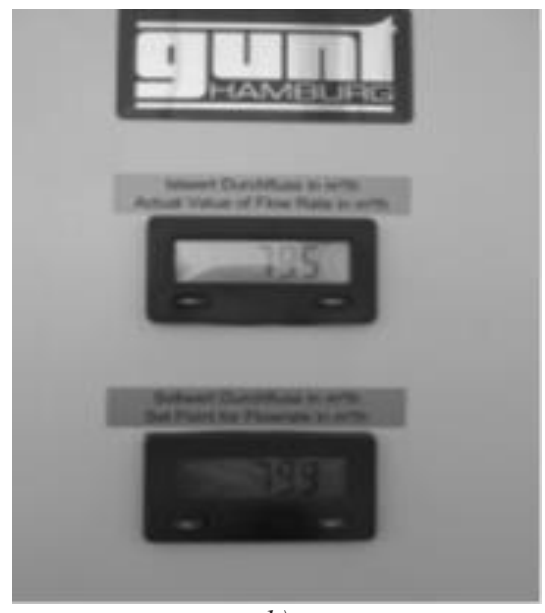

b)

Fig. 2. Channel flow measurement: (a) electromagnetic flow meter, (b) control panel display.

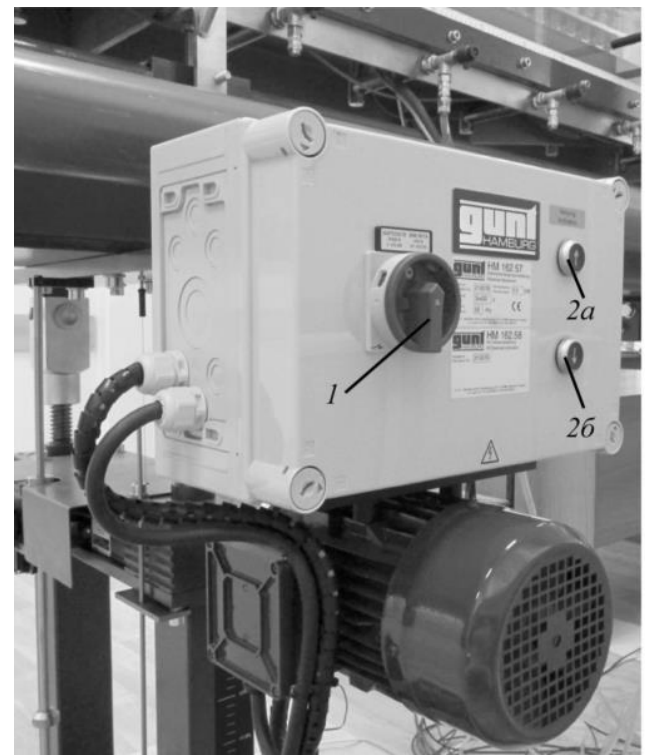

a)

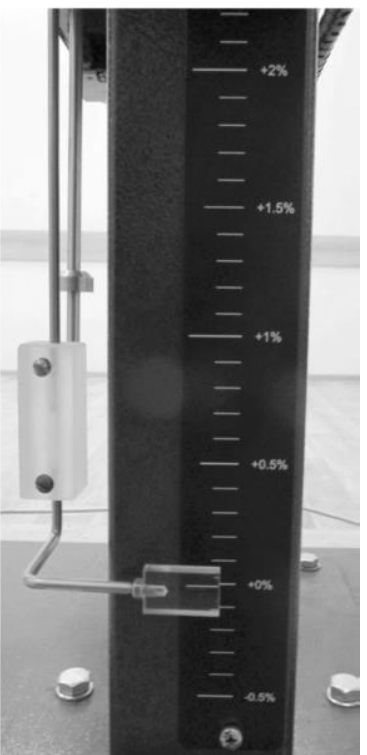

b)

Fig. 3. The jacking system for setting the channel slope: (a) the slope control panel, (b) the slope scale; 1 is switching the console on and off, 2 are the slope control keys (increasing the slope $2 \mathrm{a}$, decreasing the slope 2b). 


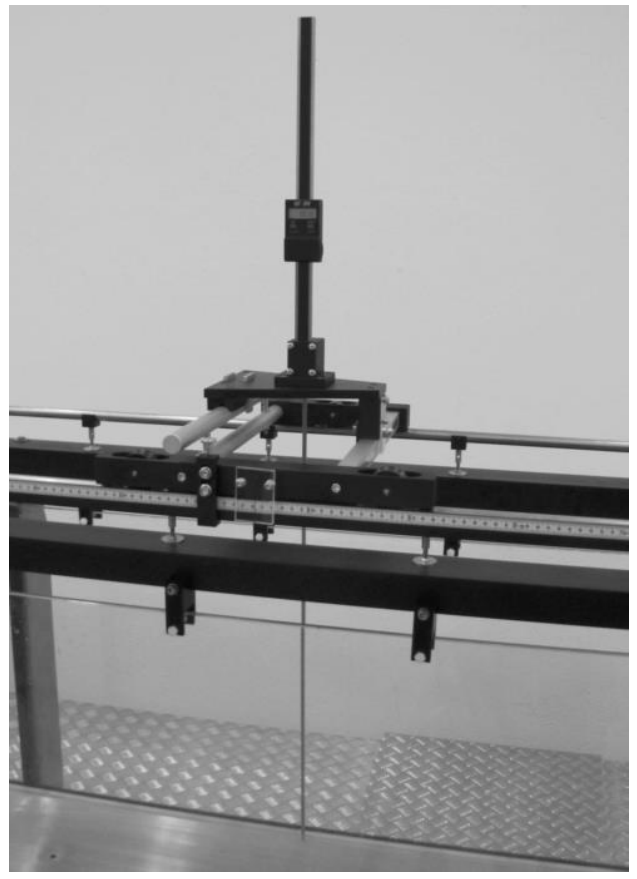

Fig. 4. Electronic level gauge

An adjustable overflow inclined threshold in the drain box maintains operating water levels in the tray. The longitudinal slope of the tray is set using an electronic Jack system equipped with remote control (figure 3a). It is fixed on the scale of the Jack system (figure $3 \mathrm{~b}$ ) and transmitted to the computer monitor as a percentage parameter. Electronic travel stops stop the Jack system when the maximum or minimum gradient is reached. Along the entire length of the tray, rails are provided for the installation of measuring devices.

Digital level sensors (probes) (electronic water level meter - figure 4), designed to measure the depth of the flow. The device consists of a probe with a needle tip, rigidly connected to a digital displacement sensor, a fixed vertical rod, and a movable carriage.

\subsection{Description of experiments}

Cross-section of the pipe has a complex shape (figure 5,6), a pipeline made up of sections with a length of $2 \mathrm{~m}$, each section has two hollow support in the bottom part dimensions 55 $\mathrm{mm}$ length and $50 \mathrm{~mm}$ depth, the width of each support equal to the width of the section of the pipeline, the distance between the supports of $1.4 \mathrm{~m}$. In addition to supporting operating as ribs of polymeric tubing, the section of present technological cavities inside duct dimensions 11 by $11 \mathrm{~mm}$, located uniformly throughout the pipe's length and running as ribs. Before carrying out the experiments, holes were cut in the upper part of the pipeline to measure the velocity of the electronic micro - coil and the water levels in the pipeline by electronic level sensors.

After laying the 7 sections of corrugated polymer pipeline in the laboratory channel, the joints in the input section of the pipe are sealed. Under different slopes and water flow is determined. The inlet pipe length was unsteady because of a large roughness and was not more than $3 \mathrm{~m}$. Local changes in depth were observed and were associated with the influence of oblique waves, which were formed under the influence of internal structural 
features of the pipe. When processing experimental data for uniform motion, these local disturbances were averaged.

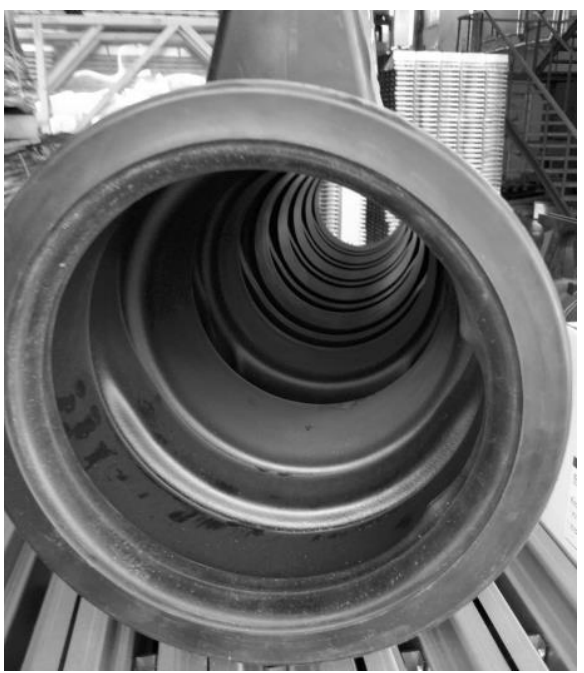

Fig. 5.Internal surface of the pipeline

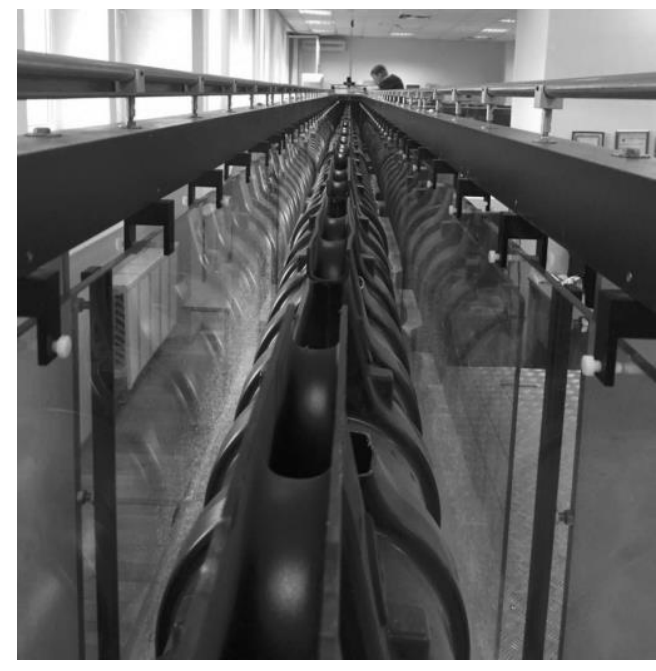

Fig. 6.Polymer pipe in the laboratory channel

The depth of the water flow was measured along the entire length of the pipeline except for the inlet section. The speed was measured at a stabilized site, at a distance from the entrance of the water flow into the pipe, with a microcomputer speed meter YuAKS 407262.001 PS (MKRS). The flow rate was measured by an electromagnetic flow meter.

After depth measurements, the filling of the $h / d$ pipeline was determined, according to which using nomograms [10], the values of the living cross-sectional area $\omega$, the hydraulic radius $R$, and the average current velocity $V$ were calculated as the ratio of the measured flow rate to the value $\omega$ :

$$
V=\frac{Q}{\omega}
$$

The experimental value of the coefficient of hydraulic resistance was calculated by the dependence:

$$
\lambda=\frac{8 g R i}{V^{2}}
$$

The values of the coefficient of equivalent roughness $k_{e}$ are obtained using the calculated value of the coefficient of hydraulic resistance $\lambda$ under the assumption of a quadratic resistance mode from the Shifrinson formula:

$$
\lambda=0.11\left(\frac{k_{e}}{d}\right)^{1 / 4}
$$

where $k_{\mathrm{e}}$ is the equivalent roughness, $\mathrm{m}$.

As you know, from the coefficient of hydraulic resistance, you can go to the Chezy's coefficient using the following relationship between these values: 


$$
C=\sqrt{\frac{8 g}{\lambda}}
$$

Applying the Manning formula

$$
C=\frac{1}{n} R^{1 / 6}
$$

and the known value of the hydraulic radius and the Chezy's coefficient; for each experiment, the value of the Manning roughness coefficient $n$ is determined.

\section{Results and Discussion}

\subsection{The results of the calculation of the program ACO Qmax «Mosvodokanal»}

The calculated results are obtained for the pipeline with a diameter of $22.5 \mathrm{~cm}$ and slopes $i=0.005, i=0.01$, close to real. In addition to these values, the program introduced the estimated costs and length of the pipeline. The calculation results are given in tables 1 and 2.

Table 1. The results of the calculations in the program ACO Qmax for the draft $i=0.005$.

\begin{tabular}{|c|c|c|}
\hline$Q\left(\mathrm{~m}^{3} / \mathrm{h}(\mathrm{l} / \mathrm{s})\right)$ & $h / d$ & $V_{\max }(\mathrm{m} / \mathrm{s})$ \\
\hline $14.3(3.88)$ & 0.24 & 0.51 \\
\hline $32.0(8.88)$ & 0.38 & 0.68 \\
\hline $66.7(18.53)$ & 0.51 & 0.88 \\
\hline
\end{tabular}

Here $Q$ is liquid flow rate; $h / d$ is pipeline filling; $V_{\max }$ is maximum flow rate

Table 2. The results of the calculations in the program ACO Qmax for the draft $i=0.01$

\begin{tabular}{|c|c|c|c|c|c|}
\hline$Q, \mathrm{~m}^{3} / \mathrm{h}(1 / \mathrm{s})$ & $h / d$ & $V_{\max }, \mathrm{m} / \mathrm{s}$ & $Q, \mathrm{~m}^{3} / \mathrm{h}(1 / \mathrm{s})$ & $h / d$ & $V_{\max }, \mathrm{m} / \mathrm{s}$ \\
\hline $14.3(3.88)$ & 0.24 & 0.51 & $49.4(13.72)$ & 0.47 & 0.79 \\
\hline $24.0(6.67)$ & 0.33 & 0.62 & $66.7(18.53)$ & 0.51 & 0.88 \\
\hline $32.0(8.88)$ & 0.38 & 0.68 & $75.5(20.97)$ & 0.56 & 0.92 \\
\hline
\end{tabular}

A comparison of tables 1 and 2 with the same flow rates and twice as different gradients reveals an exact match, which is likely to be explained by an incorrect slope value attributed to the table 1 calculation data.

\subsection{Results of pipeline filling and flow velocity measurements}

The results of the measurements of the free surface of the water flow at different flow rates and gradients are presented in figure 7. 


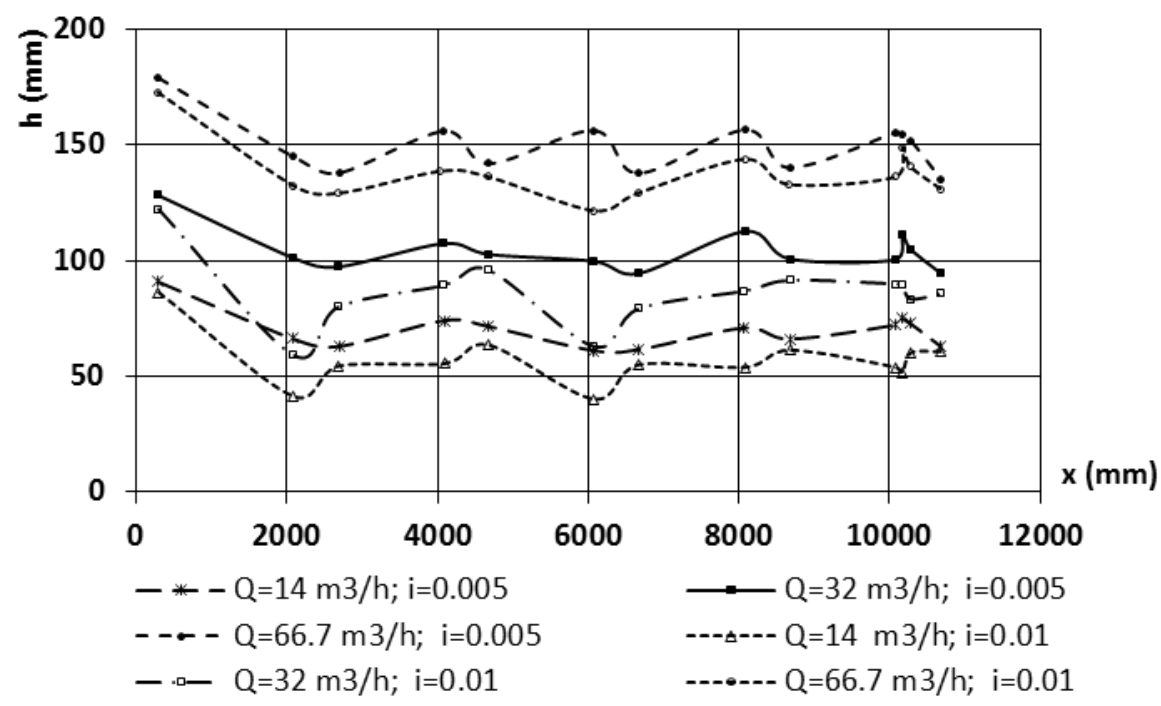

Fig. 7. Change of the free flow surface along the length of the pipe, $x$ is the distance from the beginning of the experimental channel, $\mathrm{m} ; h$ is the depth of water in the pipeline according to the readings of the electronic level sensor.

The values obtained from the experiments on the filling of the pipeline and the maximum flow velocity measured by the electronic speedometer were compared with the values obtained by the calculation program ASO Qmax (table 3).

Table 3.Comparison of calculated and experimental values

\begin{tabular}{|c|c|c|c|c|c|c|c|}
\hline$i$ & $\begin{array}{c}Q \\
\left(\mathrm{~m}^{3} / \mathrm{h}\right)\end{array}$ & $\begin{array}{c}h_{e} \\
(\mathrm{~mm})\end{array}$ & $(h / d)_{e}$ & $\begin{array}{c}V_{\text {maxe }} \\
(\mathrm{m} / \mathrm{s})\end{array}$ & $h_{\text {calc }}(\mathrm{mm})$ & $(h / d)_{\text {calc }}$ & $\begin{array}{c}V_{\text {maxcalc }} \\
(\mathrm{m} / \mathrm{s})\end{array}$ \\
\hline 0.005 & 14 & 74 & 0.33 & 0.50 & 55 & 0.24 & 0.51 \\
\hline 0.005 & 32 & 110 & 0.49 & 0.67 & 85 & 0.38 & 0.68 \\
\hline 0.005 & 66.7 & 155 & 0.69 & 0.77 & 115 & 0.51 & 0.88 \\
\hline 0.01 & 14 & 55 & 0.24 & 0.79 & 55 & 0.24 & 0.51 \\
\hline 0.01 & 24 & 74 & 0.33 & 0.83 & 75 & 0.33 & 0.62 \\
\hline 0.01 & 32 & 90 & 0.40 & 0.90 & 85 & 0.38 & 0.68 \\
\hline 0.01 & 49.4 & 108.2 & 0.48 & 0.88 & 105 & 0.47 & 0.79 \\
\hline 0.01 & 66.7 & 140 & 0.62 & 0.90 & 115 & 0.51 & 0.88 \\
\hline 0.01 & 75.5 & 155.6 & 0.69 & 0.94 & 125 & 0.56 & 0.92 \\
\hline
\end{tabular}

From comparing the data on the filling of the pipeline, it can be seen that the calculated filling for all experiments is less than the experimental one. As a result of calculations under the program, it turned out that the filling of the pipeline and the values of the flow velocity do not depend on the slope, which is not true. Apparently, the established discrepancy is connected with the inadequate choice of roughness put in the computer program.

\subsection{Results of determination of roughness coefficient and hydraulic resistance}

The roughness coefficient was determined at $Q_{f}$ flow when the pipeline section was completely filled with water, using Manning's formula, Chesy's formula, and formulas (1), (2), and (4). The value of $Q_{f}$ was taken from the graph in [10]. The results of determining 
the coefficient of roughness $n_{n}$ for conditionally full filling of the pipeline are given in table 4.

Table 4.Determination of roughness coefficient

\begin{tabular}{|l|c|c|c|c|c|}
\hline$i$ & $Q\left(\mathrm{~m}^{3} / \mathrm{h}\right)$ & \multicolumn{1}{|l|}{$h / d$} & $Q_{f}\left(\mathrm{~m}^{3} / \mathrm{s}\right)$ & $C\left(\mathrm{~m}^{0.5} / \mathrm{s}\right)$ & $n_{f}$ \\
\hline 0.005 & 14 & 0.33 & 0.018 & 26.52 & 0.023 \\
\hline 0.005 & 32 & 0.49 & 0.019 & 27.79 & 0.022 \\
\hline 0.005 & 66.7 & 0.69 & 0.022 & 33.49 & 0.019 \\
\hline 0.01 & 14 & 0.24 & 0.023 & 24.27 & 0.026 \\
\hline 0.01 & 24 & 0.33 & 0.030 & 32.15 & 0.019 \\
\hline 0.01 & 32 & 0.40 & 0.027 & 29.02 & 0.021 \\
\hline 0.01 & 49.4 & 0.48 & 0.029 & 30.98 & 0.020 \\
\hline 0.01 & 66.7 & 0.62 & 0.027 & 28.08 & 0.022 \\
\hline 0.01 & 75.5 & 0.69 & 0.025 & 26.81 & 0.023 \\
\hline
\end{tabular}

The found values of roughness coefficients for filling the pipeline at different slopes and flow rates were compared with experimental values (figure 8).

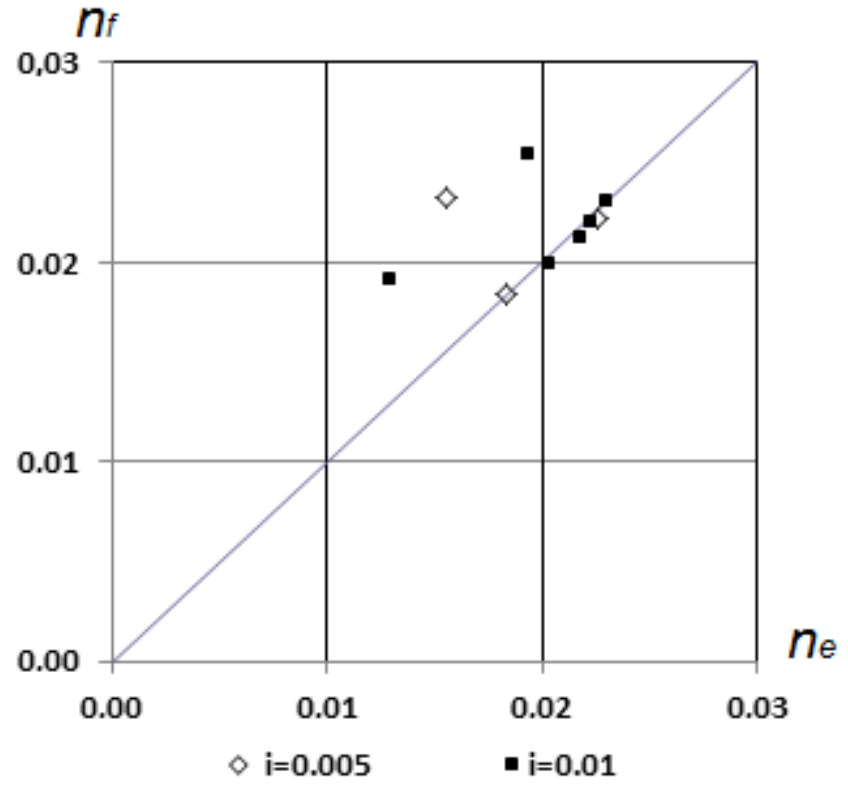

Fig. 8. Comparison of $n_{f}$ roughness coefficients obtained for $Q_{f}$ with experimental values for different pipeline filling values.

The roughness coefficient $n_{f}$ was obtained for conditions of complete filling of the pipeline agreement with the experimental values of $n_{e}$ for various values of filling the pipeline and different slopes. At small values of pipeline filling, the value of $n_{f}$ slightly exceeds the experimental values due to possible errors in determining the filling of the pipeline $h / d$ and geometric characteristics of the flow.

The obtained values of the roughness coefficient according to the reference data [11] correspond to the channels lined with rough rubble masonry (cobblestone pavement), which is physically close to the state of the inner surface of the tested pipeline.

When performing hydraulic calculations, the roughness coefficient shall be taken from the results of the experimental studies given in table 5, which do not show a distinct tendency to change depending on the filling and slope for the tested pipeline. 
Table 5. Calculation of roughness coefficient of corrugated pipeline ACO Qmax at different flow rates and slopes

\begin{tabular}{|c|c|c|c|c|c|c|c|c|c|}
\hline$i$ & $\begin{array}{c}Q \\
\left(\mathrm{~m}^{3}{ }^{-1}\right)\end{array}$ & $\begin{array}{c}h \\
(\mathrm{~mm})\end{array}$ & $h / d$ & $\begin{array}{c}V\left(\mathrm{~ms}^{-}\right. \\
\left.{ }^{1}\right)\end{array}$ & $\lambda$ & $R(\mathrm{~m})$ & $\begin{array}{c}C\left(\mathrm{~m}^{0,5} \mathrm{~s}^{-}\right. \\
\left.{ }^{1}\right)\end{array}$ & $n$ & $R e$ \\
\hline 0.005 & 14.0 & 74.0 & 0.33 & 0.35 & 0.129 & 0.041 & 24.56 & 0.024 & 56700 \\
\hline 0.005 & 32.0 & 110.0 & 0.49 & 0.46 & 0.100 & 0.056 & 27.36 & 0.023 & 102465 \\
\hline 0.005 & 66.7 & 155.0 & 0.69 & 0.64 & 0.063 & 0.066 & 34.58 & 0.018 & 169920 \\
\hline 0.005 & 20.8 & 88.5 & 0.39 & 0.40 & 0.114 & 0.047 & 26.27 & 0.023 & 76356 \\
\hline 0.010 & 14.0 & 55.0 & 0.24 & 0.52 & 0.093 & 0.032 & 29.02 & 0.019 & 64890 \\
\hline 0.010 & 20.8 & 64.0 & 0.28 & 0.45 & 0.070 & 0.035 & 33.58 & 0.017 & 63646 \\
\hline 0.010 & 24.0 & 74.0 & 0.33 & 0.60 & 0.088 & 0.041 & 29.77 & 0.020 & 97200 \\
\hline 0.010 & 32.0 & 90.0 & 0.40 & 0.61 & 0.100 & 0.048 & 27.65 & 0.022 & 115706 \\
\hline 0.010 & 49.4 & 108.2 & 0.48 & 0.72 & 0.085 & 0.056 & 30.48 & 0.020 & 160380 \\
\hline 0.010 & 66.7 & 140.0 & 0.62 & 0.72 & 0.096 & 0.064 & 28.45 & 0.022 & 183060 \\
\hline 0.010 & 75.5 & 155.6 & 0.69 & 0.72 & 0.100 & 0.066 & 27.68 & 0.023 & 191160 \\
\hline 0.010 & 60.4 & 129.0 & 0.57 & 0.73 & 0.089 & 0.060 & 29.67 & 0.021 & 192600 \\
\hline
\end{tabular}

The roughness coefficients obtained for the conditions of full filling of the pipeline are consistent with the experimental values for different values of the pipeline filling at $h / d>0.3$ and different slopes.

The obtained values of the roughness coefficient $n$ according to the reference data [11] correspond to channels lined with rough rubble masonry (cobblestone pavement) and to experimental data that is physically close to the state of the inner surface of the tested pipeline.

The coefficient of hydraulic resistance obtained from experimental data processing is of the order of $\lambda \cong 0.1$, which is close to the values obtained experimentally for pipes with internal thread [12].

\subsection{Experimental studies of the capacity of partially silted pipeline}

Additional experimental studies of the hydraulic characteristics of the corrugated polymer culvert have been conducted for the partially silted pipeline. This series of experiments was carried out by simulating partial silting of the lower part of the pipeline (tray) within the corrugation. Corrugated creases in the bottom area and hollow supports were filled with tile adhesive, which after drying was coated with epoxy glue to prevent aggregate leaching and simulate silt deposits on the surface.

In the same way as in the case of a clean pipeline, in the case of a silted pipeline simulation, depths were measured along the length of the pipeline for slopes $i=0.005$ and $i=0.01$ and different flow rates. The data show that the change in the filling of the pipeline with partial silting within the corrugation has little effect on the depth of flow in the pipeline compared to the filling of the pipe in the absence of silting.

Experimental data on the relationship of the average flow rate with the flow rate show that as well as in the absence of silting, the speed increases almost linearly with the flow rate and increases with increasing slope. Comparison of experimental values of average flow velocities in silted and clean pipeline shows that they practically do not differ. The comparison of experimental data shows that the roughness value practically does not detect the influence of slope, filling, and partial silting of the pipeline.

The hydraulic characteristics of the polymer culvert were studied in the laboratory channel to compare the calculated values with the measured values. 
As a result of measurements of pipeline filling and flow rates, experimental values of water flow rate were obtained for different values of pipeline filling $h / d$ and water flow $Q$. at the same flow rates, the calculated value of pipeline filling with water for all experiments was less than the experimental value. The calculated values of the average speed were the same for different slopes, which is not confirmed by experimental data. Most likely, this is due to an incorrect value of the roughness coefficient embedded in the computational program.

The measured flow rate and velocity determine the experimental value of the roughness coefficient of the corrugated pipeline. This value is obtained for different values of filling and hydraulic radius of the pipeline, including the complete filling of the pipeline with water.

The experimental values of the hydraulic resistance coefficient $\lambda$ and the coefficient Care obtained using the Manning and Chezy formulas [13-18]. The values of the Reynolds numbers Re for the water flow are Determined.

Hydraulic characteristics of a partially silted culvert corrugated pipeline made of polymer material, which is used for receiving contaminated surface runoff from urban areas, are investigated. It is shown that they differ little from the hydraulic characteristics of the pure water flow in the same pipeline.

The results of the analysis presented in the article are obtained for the first time, are practically significant for design and operating organizations, should be taken into account in the automated calculations of the capacity of polymer corrugated culverts.

\section{Conclusions}

The pipelines considered in the article are used in surface drainage systems. Accurate roughness values are required for hydraulic calculations. The experimental studies performed are used to verify the hydraulic calculation methodology developed by "Mosvodokanal."

Based on the experimental hydraulic studies and evaluation of the calculated data, the following conclusions can be drawn:

In the program, ACO Qmax, producing a hydraulic calculation of the studied pipelines, laid a smaller value of roughness than it turned out due to laboratory experiments.

The experimentally obtained roughness value varies little depending on the slope and filling. The recommended manning roughness coefficient is $n=0.021-0.022$.

The coefficient of hydraulic resistance obtained from the processing of experimental data is of the order of $\lambda \cong 0.1$, which is close to the values obtained for pipes with internal thread.

With a concentrated end flow from the well into the pipeline, there is an initial section of the length of about $15 d$, within which an uneven motion develops with a depth exceeding the depth of uniform motion, which should be taken into account when determining the diameter of the pipe. 


\section{References}

1. Suetina T.A., Chernykh O.N., Burlachenko A.V. IOP Conf. Series: Materials Science and Eng. (2018)

2. Zannurov T.A., Piskunov A.A., and Petropavlovskikh O.K. Naukovedeniye (Electronic Materials vol 9(4) (Moscow: Publishing company «World of science», LLC), (2017)

3. Dudin S., Zemenkov Y., Gulkov A., and Zemenkova M. IOP Conference Series: Earth and Environmental Science vol 459(4) p 052092, (2020)

4. Prodous O.A., and Terekhov L.D. Water treatment and water supply vol 9 (Moscow: Watermagazine) p 44, (2018)

5. Ryabov I.V. Regulirovaniye vnutrennikh napryazheniy $v$ gruntozasypnykh arochnykh sooruzheniyakh iz metallicheskikh gofrirovannykh konstruktsiy (Kirov: Vyatka state University) p 135, (2016)

6. Firat Sever V and Ehsani M 2019 Pipelines Planning and Design - Proceedings of Sessions of the Pipelines 2019 Conference p. 117, (2019)

7. Kotovchikhina E.A., Gildenberg A.Yu., and Ivanova N.V. Aktualniye problemy stroitelstva, GKH $i$ tekhnosfernoy bezopasnosti: materialy VI Vserossiyskoy (s meghdunarodnym uchastiyem) nauchno-tekhnicheskoy konferencii molodykh issledovateley (Volgograd: VGTU) p. 60. (2019)

8. Malofeyev A.G., Znamenskaya T.V., and Shuvayev A.N. Arkhitekturno-stroitelniy $i$ doroghno-transportniy kompleksy: problemy, perspektivy, innovacii: sbornik materialov III Meghdunarodnoy nauchno-prakticheskoy konferencii (Omsk: Sibirskiy gosudarstvenniy avtomobilno-doroghniy universitet (SibADI)) p. 258, (2019)

9. Bojko M., and Kozubková M. MATEC Web Conf. XXI Int. Sc. Conf. - The App. of Experimental and Numerical Methods in Fluid Mechanics and Energy 168 p. 02011, (2018)

10. Linke U. HM162. Experimental Flume 309x450mm(Hamburg: GUNT Gerätebau GmbH) p. 52.

11. Passport of the state standard of liquid volume unit in the range of volume flow values from 0 to $130 \mathrm{~m} 3 / \mathrm{h}$ № LGG-0001 (Moscow: NRU MGSU), (2017)

12. Kurganov A.M., and Fedorov N.F. Spravochnik po gidravlicheskim raschetam sistem vodosnabzheniya i kanalizatsii (Leningrad: Stroyizdat), p. 408, (1973)

13. Kiselev P.G. Spravochnik po gidravlicheskim raschetam (Moscow: Energy) p. 312, (1972)

14. Millionshchikov M.D. Turbulentnyye techeniya $v$ pogranichnom sloye $i v$ trubakh (Moscow: Nauka) p. 52, (1969)

15. Borovkov V.S., Bryanskaya Y.V., and Ostyakova A.V. Water Resources vol 45(2) (Moscow: Nauka) p. 169, (2018)

16. Borovkov V.S., Bryanskaya Y.V., and Ostyakova A.V., IOP Conf. Series: Materials Sc. and Eng. p 042046, (2018)

17. Bryanskaya Y. Int. J.of Applied Eng. Research No 3 p 1694, (2016)

18. Ostyakova A.V. Power Technology and Eng. vol 47(1) p. 12, (2013)

19. Bryanskaya Y.V., and Ostyakova A.V. E3S Web of Conferences, FORM-2019 (Tashkent (Uzbekistan): Tashkent Institute of Irrigat. and Agricult. Mechaniz. Eng.) vol 97 p 05006, (2019)

20. Iliin V.V., and Vyatkina S.D., Aktualniye problemy arkhitektury, stroitelstva, energoeffektivnosti I ecologii: sbornik trudov (Tyumen: Tyumen industrial University) p. 109, (2016)

21. Mitrakovich A.I. Melioration vol 81(3) p. 29, (2017) 
22. Volgin G. E3S Web of Conf. FORM-2019 (Tashkent; Uzbekistan: Tashkent, Tashkent Institute of Irrigation and Agricultural Mechanization Engineers,97 p. 05031, (2019)

23. Mikhailovsky Y. MATEC Web of Conferences. International Scientific Conference "Investment, Construction, Real Estate: New Technologies and Special-Purpose Development Priorities". ICRE-2018 (Irkutsk), 212, p. 06006, (2018)

24. Dezhina I. and Orlov V. E3S Web of Conf. 22nd Int. Sc. Conf. on Construction the Formation of Living Environment. FORM-2019 (Tashkent:Tashkent Institute of Irrigation and Agricultural Mechanization Engineers), 97 p. 02003, (2019)

25. Chemezov D.A. Theoretical \& applied science vol 45(1) p 14, (2017)

26. EN 752:2008 (D)

27. Nikora V.I., Stoesser T, Cameron S.M. and Stewart M. J. of Fluid Mechanics vol 872 p. 626, (2019)

28. Renard N and Deck S Cambridge University Press, 790, p. 339, (2016)

29. Kim T, Blois G, Best J.L., and Christensen K.T. J. Fluid Mech.vol 887 A3, (2020)

30. Chan L., MacDonald M, Chung D, Hutchins N. J. Fluid Mech. vol 771 p. 743, (2015)

31. Zhang S.C., Zhang Y.L. and Fang Z.M. 26th IAHR Symposium on Hydraulic Machinery and Systems vol 15(5) p 1-5, (2012)

32. Anderson W.J. Fluid Mech. vol 789, p. 567-588, (2016)

33. Chen T. IOP Conf. Ser.: Earth and Environmental Science. 252(5) p. 052120, (2018)

34. Han J, Yang L, Huang J, Jiang J and He Y. IOP Conf. Series: Material Science and Engineeringvol 544(1) p 012035 (1-7), (2018)

35. Menshykova M and Guz I.A. Int. J. of Mechanical Sc. vol 88 p 289-299, (2014) 